\title{
Covid-19 Pandemisinin Veteriner Hekimler ve Hayvanlar Üzerine Etkileri
}

\section{The Impact of Covid-19 Pandemic on Animals and Veterinarians}

\section{Alev Akdoğan Kaymaz ${ }^{1}$ (I)}

1 İstanbul Üniversitesi-Cerrahpaşa, Veteriner Fakültesi, İç Hastalıkları Anabilim Dalı, İstanbul, Türkiye

ORCID: A.A.K. 0000-0003-4457-6856

Sorumlu Yazar/Corresponding Author: Alev Akdoğan Kaymaz,

İstanbul Üniversitesi-Cerrahpașa, Veteriner Fakültesi, İç Hastalıkları Anabilim Dalı, İstanbul, Türkiye

E-posta: aakaymaz@gmail.com

Geliș tarihi/Submitted: 28.06.2021 İlk revizyon/First Revision Received: 10.08.2021 Son Revizyon/Last Revision Received: 31.08 .2021 Kabul Tarihi/Accepted: 12.09.2021

Atıf/Citation: Akdogan Kaymaz A. The impact of Covid- 19 pandemic on animals and veterinarians. Sağlık Bilimlerinde İleri Araştırmalar Dergisi 2021; 4(Suppl.1): S75-S82.

https://doi.org/10.26650/JARHS2021-958904
ÖZ

Bu çalışmada, yurdumuzda COVID-19 pandemi sürecinin hayvanlar, hayvan yakınlar ve Veteriner Fakültesi’nde klinik eğitimi alan öğrenciler, klinik akademisyenler ve serbest veteriner hekimler üzerine olan etkileri değerlendirilmiştir. Konu ile ilgili ulaşılabilen kaynaklar incelenerek yurdumuzdaki ve dünyadaki durum ortaya konulmuştur. Ayrıca, COVID-19 etkeninin özelliği ile hayvan türleri arasındaki farklılıklara ait bilgiler verilmiştir. Koronaviral enfeksiyonun yaygın bir şekilde görüldüğü köpekler ve özellikle kedilerde yapılacak yeni çalışmalar COVID-19'un hayvanlarda görülen etkileri, bulaşma biçimleri ve hastalık seyri ile ilgili bilgi sahibi olunmasına yardımcı olacaktır.

Anahtar Kelimeler: Pandemi, Covıd-19, veteriner hekimliği, hayvan hakları

\section{ABSTRACT}

The effects of the COVID-19 pandemic process on animals, animal caregiver, and veterinary students, clinical academicians and self-employed veterinarians in our country were evaluated in this study. By examining the available resources on the subject, the situation in our country and in the world has been revealed. In addition, information is given on the characteristics of the COVID-19 agent and the differences between animal species. New studies in dogs and especially cats, in which coronavirus infection is common, will help us to provide information concerning the effects of COVID-19 in these animals and the contamination patterns and course of the disease.

Keywords: Pandemic, Covid-19, veterinary medicine, animal rights 


\section{GíRIŞ}

Çin'in Vuhan şehrinde, 17 Kasım 2019'da tespit edilen ilk vakada yapılan değerlendirmeler sonucu tespit edilen hastalık COVID-19 (SARS-CoV-2 - şiddetli akut solunum sendromu koronavirüs-2) olarak tanımlanmıştır $(6,36)$. Kısa sürede tüm dünyayı saran bu salgın 30 Ocak 2020'de Dünya Sağlık Örgütü (WHO) tarafından halk sağlı̆̆ı için uluslararası acil bir durum olarak değerlendirilmiş ve 11 Mart 2020'de pandemi ilan edilmiştir $(18,20,21)$. Günlük yaşantımızda birçok değişikliğe neden olan COVID-19 pandemisinin özellikle sağlık, eğitim ve ekonomide belirgin etkileri olmuştur.

Koronavirüs, hayvanlarda ilk olarak 1930 yılında akut solunum yolu enfeksiyonu (enfeksiyöz bronşit virüsü, IBV) olan evcil bir tavukda tanımlanmış (9) olmasına karşın, insanlarda 1960 yılında keşfedilmiştir. Bu nedenle, veteriner hekimler tıp hekimlerine nazaran uzun yıllar boyunca solunum veya gastrointestinal bozuklukluklarla seyreden koronavirüslere karşı daha çok tecrübe kazanmışlardır. Koronaviruslar; insanlar, çiftlik hayvanları, pet hayvanları, atlar, yarasalar, laboratuvar hayvanları, yaban hayvanları ve deniz balinalarında hastalık oluşturabilmektedirler (38). Alfa- ve beta-koronavirüsler sadece yarasalar ile diğer memelileri enfekte ederken, gamma- ve delta-koronavirüsler kuşlarda hastalık oluştururlar, ancak bazıları memeli (domuz) ve balıklara bulaşabilmektedir $(7,45)$. Köpeklerde iki alfa-koronavirüs (köpek enterik koronavirüsleriCCoV-I ve CCoV-II) ile bir beta-koronavirüs (köpek solunum koronavirüsü- $\mathrm{CRCoV}$ ) hastalık oluşturur $(8,22)$. Kedilerde ise enfeksiyona alfa-koronavirüs (kedi infeksiyöz peritonit virüsü- FIPV ve kedi enterik koronavirus- FECV) neden olur. Hastalık; özellikle bağışıklığı baskılanmış çok genç ve/veya yaşlı evcil ve yabani kedilerde temel olarak solunum sistemi, batın boşluğu ve merkezi sinir sistemini etkileyerek şiddetli enterit ve enfeksiyöz peritonite neden olur (42). Kedilerde enfeksiyöz peritonit hastalığının, kedi enterik koronavirüsün $\mathrm{S}$ geninin mutasyonu sonucu oluştuğu kabul edilmektedir (37).

Bu çalışmada; COVID-19 pandemi sürecinde hastalığın oluşumunda hayvanlara atfedilen rol ve bu role ilişkin terk etme ve/veya öldürme gibi yaşanan olumsuzlukların sebepleri ile bu süreçte hem hayvanların hem de insanların mağduriyetleri irdelenmiştir.

\section{COVID-19 Pandemisinde Yaşanan Olumsuzluklar}

COVID-19 pandemisi; günlük yaşamımızda önemli bir yere sahip olan hayvanlar ve hayvanların sağlığ kadar özellikle zoonozlara karşı halk sağlığ için mücadele veren veteriner hekimler için başa çıkılması gerekli bazı sorunlara yol açmıştır. Bununla birlikte, halen öğrenci statüsünde olan genç veteriner hekim adayları da bu süreçten olumsuz olarak etkilenmişlerdir. Bu süreçte veteriner hekimler aşı çalışmalarına katılarak hem insan hem de hayvan sağllğı konusunda çalışırken bir taraftan da hayvanların haklarını korumak üzere hayvan yakınlarına pandemi konusunda bilgilendirmelerde bulunmuşlardir.

\section{Hayvanlar Açısından COVID-19 Pandemisi} Süreci

Hayvanlarda uzun zamandır bilinen koronavirüslerle ilgili enfeksiyonlar kanatlllar, domuz, ruminantlar, yaban hayvanları, at, eşek, tek hörgüçlü deve, köpek ve kedilerde yaygın bir şekilde görülmektedir. Genellikle solunum yolu problemleri ve enterit oluşturan bu virüslere karşı bazı hayvan türlerinde aşılama yapılmasına karşın, bağışıklığın ileri derecede düşmesi nedeni ile özellikle kanatl ve çiftlik hayvanlarında büyük ekonomik kayıp oluşmaktadır.

SARS-CoV-2'dan önce koronavirüslerin doğal konakçısı olmadığı varsayılan yarasalar, pandemi ile birlikte artık doğal bir alfa-koronavirüs ve beta-koronavirüs rezervuarı olarak kabul edilmektedir $(5,35)$. Bununla birlikte, yarasaların Çin'de bir besin ve geleneksel Çin tıbbında bir kaynak olarak kullanılması zoonotik koronavirüslerin bulaşı riskini arttırmaktadır (44). SARS-CoV-2 enfeksiyonunun insandan insana bulaştığı Ocak 2020 tarihinde doğrulanmış (4), ancak henüz kesin olarak tanımlanmamakla birlikte tüm dünyada ölümlerin hızlı bir şekilde artmasıyla hastalığın yayılmasında yabani hayvanlar, çiftlik hayvanları veya insanlarla birlikte aynı ortamı pay- 
laşan evcil hayvanların bir rolü olup olmadığı sorusunu akla getirmiştir (32).

Deneysel modelleme çalışmaları, gelincik ve vizonların SARS-CoV-2 enfeksiyonuna karşı hassas olduğunu göstermektedir $(2,13,16,28,40)$. Vizonlar; SARS-CoV-2 ile enfekte hayvanlar ve insanlardan hastalığı kapabilmekte, hatta enfekte olduklarında hastalığ 1 çiftlikteki diğer vizonlara ve bu hayvanlarla ilgilenen kişilere bulaştırabilmektedirler (10). Vizonlardaki SARS-CoV-2, ilk kez 23 Nisan 2020'de Hollanda'da iki vizon çiftliğinde bildirilmiştir $(31,32)$. $\mathrm{Bu}$ durumu takiben, Mayıs 2020'de Avrupa'nın en büyük vizon kürkü üreticisi Danimarka'da ilk vakalar rapor edilmiştir (12). Bu çiftliklerde çalışan işçilerin $\% 68$ 'inde virüsün pozitif olması veya SARS-CoV-2 antikorlarının saptanması ile Danimarka'da 4 Kasım 2020'de 13.000.000'dan fazla hayvan itlaf edilmiş ve vizon çiftlikleri kapatılmıştır $(32,34)$. Daha sonra, İspanya, İsveç, İngiltere, ABD, Yunanistan, Fransa, Kanada, Litvanya ve Polonyada da pek çok vaka rapor edilmiştir $(26,31,32)$. Ancak, antropo-zoonotik salgınlar sadece vizon çiftliklerinde belirlenmiş ve bu çiftliklerdeki hayvanların tamamı itlaf edilmiştir (34).

Evcil kedilerin ve köpeklerin ise sahiplerinin enfekte olması sebebi ile doğal olarak hastalığa yakalandıkları tespit edilmiştir (19). Son zamanlarda, Kuzey İtalya'da 919 evcil kedi ve köpek üzerinde yapılan bir çalışmada; PCR testleri pozitif olmadığ 1 halde değerlendirilen köpeklerin \% 3.3'ünde ve kedilerin ise \% 5.8'inde SARS-CoV-2 ve anti-SARS-
CoV-2 nötralize edici antikorların varlığı tespit edilmiştir (33). Slovenya'da gastrointestinal belirtileri görülen COVID-19 hastası ile temas halinde olan iki yaban gelinciğinde SARS-CoV-2 pozitif olarak tespit edilmiștir (25). Brezilya'da birlikte yaşadıkları hasta yakını COVID-19 ile enfekte olan 29 köpekten 9'unun ve 10 kediden 4 'ünün SARS-CoV-2 ile enfekte veya seropozitif olduğu belirlenmiştir (3).

İlk köpek vakaları, Hong Kong'da yaşayan ve SARS-CoV-2 ile enfekte hayvan yakını ile temas halinde olan biri 17 yaşında bir Pomeranian, diğeri ise 2 yaşında bir Alman çoban köpeğinde tespit edilmiştir (41). Hayvanlar, enfeksiyonla ilgili herhangi bir klinik belirti göstermemelerine rağmen PCR testlerinde düşük oranda SARS-CoV-2 antikorları tespit edilmiştir. Ancak, enfekte Alman çoban köpeği ile temas halinde olan diğer melez köpeğe hastalığın bulaşmadığı tespit edilmiştir. Üçüncü pozitif vaka ise Amerika Birleşik Devletleri, Kuzey Carolina'da birlikte yaşadığı üç aile bireyi de SARS-CoV-2 pozitif olan ve hapşırma, öksürük gibi hafif solunum belirtileri gösteren bir pug köpekte bildirilmiştir (23). Ancak, ABD Tarım Bakanlığı Ulusal Veterinerlik Hizmetleri Laboratuvarı pozitif olan test sonucunu onaylamamıştır. Bununla birlikte, ABD'de doğrulanmış ilk SARS-CoV-2 enfeksiyonu New York'da yaşayan bir Alman çoban köpeğinde rapor edilmiştir (47).

Dünya Hayvan Sağlığı Örgütü (OIE) tarafından kedi ve köpek vakaları altı aylık periyodlar ile listelenmekte ve güncellenmektedir. Aralık 2020 verile-

Tablo 1. Türlere ve bölgelere göre dünya çapında rapor edilen salgın sayısı ( $\mathrm{n}=552)$ (31 Mayıs 2021 verilerine göre) (OIE, SARS-COV-2 Durum Raporu-1) (30).

\begin{tabular}{|l|l|l|l|l|l|l|l|l|l|l|}
\hline $\begin{array}{l}\text { Türler } \\
\text { Bölge }\end{array}$ & Kedi & Köpek & Vizon & Diger & $\begin{array}{l}\text { Pet } \\
\text { gelincik }\end{array}$ & Aslan & Kaplan & Puma & $\begin{array}{l}\text { Kar } \\
\text { leopar }\end{array}$ & Goria \\
\hline Afrika & & & & & & & & 1 & & \\
\hline Amerika & 67 & 66 & 20 & 1 & & 2 & 7 & 2 & 1 & 1 \\
\hline Asya & 10 & 15 & & & & & & & & \\
\hline Avrupa & 24 & 4 & 326 & & 1 & $2^{*}$ & $1^{*}$ & & & \\
\hline TOTAL & 101 & 85 & 346 & 1 & 1 & 4 & 8 & 3 & 1 & 1 \\
\hline
\end{tabular}

^İsveç'te bir aslan ve bir kaplan aynı bölgedendir ve bu nedenle bu tabloda sadece 1 salgın olarak temsil edilmektedir. 
rine göre Belçika, Hong Kong, ABD, Fransa, İspanya, Almanya, Birleşik Krallık, İtalya, İsviçre, Rusya, Danimarka, İsveç, Şili, Japonya, Brezilya ve Arjantin’den SARS-CoV-2 ile enfekte pek çok kedi vakası bildirilmiştir (29).

Kedilerde ilk vaka; birlikte yaşadığı sahibi İtalya’dan yaşamını sürdürdüğü şehir olan Brüksel'e dönüş yapan ve gastroenterit belirtileri olan bir kedide tespit edilmiştir (11). İkinci vaka ise SARS-CoV-2 ile enfekte olduğu halde herhangi bir klinik belirti göstermeyen, ancak solunum sekresyonları ile dışkısında virüs saptanan bir kedide bildirilmiştir (27). Yine, New York'da benzer şekilde iki kedi vakası rapor edilmiştir. Bu vakaların her ikisi de hafif solunum rahatsızlığı semptomları göstermesine karşın, bir kedinin birlikte yaşadığı ev halkından hiç kimsenin COVID-19 ile enfekte olmadığ halde diğer kedinin hasta yakınının pozitif olduğu belirlenmiştir. Bununla birlikte, PCR testi pozitif olan 6 kedide hastalığın insanlardan kedilere bulaştığ

Köpek ve kedilerde SARS-CoV-2 enfeksiyonunun doğal yoldan sporadik olarak görülebildiği de bildirilmiştir (17).

Kedigiller sınıfında yer alan ve hayvanat bahçelerinde kafeste yaşayan kaplan, aslan, puma (Puma concolor) ve kar leopar1 (Panthera uncia)'nda da sporadik SARS-CoV-2 enfeksiyonları bildirilmiştir (15).

Ülkemizde ise herhangi bir hayvanda SARSCoV-2 enfeksiyonuna ilgili henüz bildirim yapılmamıştır. SARS-CoV-2 virüsünün hayvanlardan yayıldı ̆̆ını gösteren bir kanıt olmamasına rağmen (39), diğer ülkelerde (14) olduğu gibi ülkemizde de bu süreçte bazı hayvan yakınları COVID-19 enfeksiyonunun hayvanlardan insanlara geçtiği düşüncesi ile beraber yaşadıkları hayvanlarını terk etmişlerdir. $\mathrm{Bu}$ sayede ülkemizin kanayan bir yarası olan ve günden güne sayıları artan sokak hayvanlarına yenileri eklenmiştir. Veteriner Hekimler Odaları ve Türk Veteriner Hekimleri Birliği (TVHB) Merkez Konseyi, yurdumuzda sokağa bırakılan evcil hayvan sayısının pandemi döneminde 20 kat arttığını belirterek insanlara virüs bulaştırıyor iddiası nedeniyle çok sayıda evcil hayvanın bu dönemde sokağa bırakıldığını açıklamıştır (43). Bununla birlikte, bu süreçte Avru- pa ülkelerinde olduğu gibi sokaktan veya barınaklardan hayvan sahiplenilmeye de devam edilmiştir.

\section{Veteriner Hekimler Açısından COVID-19}

\section{Pandemisi Süreci}

Veteriner hekimler bu süreçte gerekli hijyen, randevu sistemi vb. önlemleri alarak hem özel klinikler hem de hayvan hastanelerinde rutin olarak hasta bakmaya devam etmişlerdir. Büyük hayvan alanında çalışan meslektaşlarımız sahada çiftlik hayvanlarının düzenli olarak aşılamalarını ve muayeneleri gerçekleştirmiştir. Üniversite hastanelerinde görev yapan klinisyen veteriner hekimlerimiz ise günlük hasta muayenelerinin yanı sıra veteriner hekimliği öğrencilerine hem çevrimiçi hem de hasta başında yüz yüze eğitim programlarını gerçekleştirmişlerdir. Pandemi sürecinde devam zorunluluğunun bulunmaması nedeni ile öğrencilerin çevrimiçi derse katılım oranı oldukça düşük olmuştur. Diğer taraftan, üniversite öğrencilerinin pandemi sürecinde eğitimleri dışında psikolojik, sosyal, aile içi ve sağlıklarına ilgili çeşitli sorunlar yaşamaları eğitimlerini negatif yönde etkilemiştir.

İstanbul'da eğitim alan üniversite öğrencileri $(\mathrm{n}=2583)$ üzerinde yapılan bir anket çalışmasında; öğrencilerin COVID-19 önlemlerinin ekonomik sonuçları nedeniyle mali zorluklar yaşadıkları, yurtların kapatılması nedeniyle öğrencilerin büyük çoğunlugunun daha kalabalık nüfusa sahip aile evlerine geri döndükleri, bunun sonucunda sosyal etkileşimlerinin çoğunlukla dijital ortama kaydığı ve öğrencilerin yüksek düzeyde anksiyete ve sıkıntı yaşadıkları belirtilmiştir (46).

Farklı ülkelerde veteriner hekimliği eğitimi alan 50 öğrenci üzerinde yapılan bir anket çalışmasında ise öğrencilerin çoğu uygulamalı ders konularının çevrimiçi öğrenilmesinin zor olduğu ve veteriner hekimlik mesleği öğrenimlerinin sadece çevrimiçi eğitim sistemi ile kazanılamayacağını düşündükleri belirlenmiştir (24).

Hastalıkları nedeni ile hayvanlarını kliniklere veya hayvan hastanelerine getiren hayvan yakınlarının aşılı veya COVID-19 açısından negatif olup olmad1ğının bilinememesi özellikle aşılama süreci öncesinde sorun oluşturmuş ve maalesef pek çok meslekta- 
şımız COVID-19 enfeksiyonu nedeni ile hayatını kaybetmiştir. Veteriner hekimlerin sağlık mensubu olarak kabul edilmemesi ve aşı için belirlenen öncelikli risk grubu içinde yer almaması sebebi ile aşılanmamaları alınan bireysel önlemlere rağmen bu sayının artmasına katkı sağlamıştır.

Veteriner hekimler, gerek hayvan hastalıkları gerekse gıda hijyeni ve hastalıkları, aşı çalışmaları ve zoonoz hastalıklar yönünden halk sağlığı konularında da hizmet vermektedirler. Bugün Turkovac adı ile tescillenen yerli COVID-19 aşısının geliştirilmesinde yine bir Veteriner hekim olan Prof.Dr. Aykut Özdarendeli öncülük etmiştir.

Diğer taraftan, meslek alanı içinde olması nedeni ile Veteriner hekimler zoonotik hastalıklar konusunda da yaygın bir şekilde çalışmakta olup, hayvan, insan ve çevre sağllğ 1 ile hayvan refahı gibi konularda multidisipliner bir çalışma gerektiren bir yaklaşım içerisinde tek sağlık yaklaşımını vurgu yapmaktadırlar.

Bu dönemde 5199 sayılı Hayvanları Koruma Kanunu'na göre hayvanların mal olarak değerlendirilmesi ve yeni yapılanmakta olan Hayvan Hakları Yasası'nın halen yürürlüğe girmemiş olması terk edilen veya sokağa bırakılan hayvanlar konusunda bir şeyler yapılabilmesini engellemiştir. Bu eylemleri yapan kişiler için herhangi bir cezai işlem uygulanmamıştır.

Bununla birlikte, yine bu dönemde ülkemizde sokağa çıkma yasağı uygulanan saatlerde gönüllü kişiler tarafından sokaklara terk edilen bu hayvanlara yemek ve su verilerek ihtiyaçları sağlanmaya çalışılmıştır. Böylece sokaklarda yaşayan kedi ve köpekler bu kısıtlı zamanlarda İstanbul'un tadını çıkarmışlardır.

\section{SONUÇ}

COVID-19 pandemisi, her alanda olduğu gibi veteriner hekimler, Veteriner Hekimliği öğrencileri ve hayvanlar üzerinde de çeşitli olumsuz etkilere neden olmuştur.

Veteriner Hekimlik eğitimin çevrimiçi olarak yapılması ve uygulamalı derslerin yapılamaması genç meslektaş adaylarının meslek için yeterli bir eğitim alamamalarına yol açmıştır.
Hastalığın artık insanlardan hayvanlara geçtiğinin kabul edildiği son dönemde yaban hayvanı, çiftlik hayvanı ve egzotik hayvanların pek çoğu bakımsızlık, terk edilme veya kitlesel itlaf gibi nedenlerden dolayı artık aramızda yaşamamaktadır. Pandemi kısıtlamaları sürecinde evden çıkılmasının yasaklanması sonucu başlangıçta kimi zaman yalnızlık giderme, kimi zaman da dışarı çıkma bahanesi yaratmak için barınaklardan özellikle kedi ve köpek sahiplenme oranı artış göstermiş, ancak daha sonra bu hayvanların COVID-19 bulaştırma ihtimalinin gündeme gelmesi ile birlikte bu hayvanların önemli bir bölümü sokağa terk edilmiştir. Halen evlerinde yaşamaya devam eden kedi ve köpekler ise bu süreçte yoğun olarak aile bireyleri ile bir arada kalmaktadırlar. Çoğu zaman köpekler için cazip olan bu durum kediler için bir azaba dönüşebilmektedir. Bunun yanı sıra, pandemi kısıtlamalarının gevşetilmesiyle birlikte, aile bireylerinin normal çalışma sürecine geçmesi ardından evde yalnız kalacak olmalarının doğurabileceği ayrılık anksiyetesi gibi bazı davranış sorunları da göz ardı edilmemelidir. Bizlerle yola devam edenler ise aynı bizlerin yaşadığına benzer refah yoksunluğu ve davranış sorunlarıyla yüz yüze kalacaklardır. Yeter ki, her biri yaşamlarımıza büyük anlam ve derinlik katan bu can dostlarımızın yaşam haklarını onlardan esirgemeyelim.

Hakem Değerlendirmesi: Dış bağımsız.

Peer Review: Externally peer-reviewed.

Çıkar Çatışması: Yazar çıkar çatışması beyan etmemiştir.

Conflict of Interest: Author declared no conflict of interest.

Finansal Destek: Yazarlar finansal destek beyan etmemişlerdir.

Financial Disclosure: Authors declared no financial support.

\section{KAYNAKLAR}

1. Barrs VR, Peiris M, Tam K, Law P, Brackman CJ, To E, et al. SARS-CoV-2 in quarantined domestic cats from COVID-19 households or close contacts, Hong Kong, China. Emerg Infect Dis 2020;26:3071-4. 
2. Blanco-Melo, D., Nilsson-Payant, B. E., Liu, W. C., Uhl, S., Hoagland, D., Mølleret, R., et al. Imbalanced host response to SARSCoV-2 drives development of COVID-19. Cell 2020;181(5):1036-45.

3. Calvet GA, Pereira SA, Ogrzewalska M, Pauvolid-Correa A, Resende PC, Tassinari WS et al. Investigation of SARS-CoV-2 infection in dogs and cats of humans diagnosed with COVID19 in Rio de Janeiro, Brazil. PLoS ONE 2021;16(4):e0250853. doi.org/10.1371/journal. pone. 0250853 .

4. Chan JF, Yuan S, Kok KH, To KK, Chu H, Yang J, et al. A familial cluster of pneumonia associated with the 2019 novel coronavirus indicating person-to-person transmission: a study of a family cluster. Lancet 2020;395(10223):514-23.

5. Chen J, Liu T, Deng HQ, Xiao N, Zhou J. A new species of Murina bats was discovered in Guizhou Province, China. Cave Res 2017;2:111.

6. China's First Confirmed Covid-19 Case Traced Back to November 17". South China Morning Post; 2020 March. Available from: URL: https://www.scmp.com/news/china/society/ article/3074991/coronavirus-chinas-firstconfirmed-covid-19-case-traced-back.

7. Cui J, Li F, Shi ZL. Origin and evolution of pathogenic coronaviruses. Nat Rev Microbiol 2019;17(3):181-92.

8. Escutenaire $\mathrm{S}$, Isaksson $\mathrm{M}$, Renström LHM,Klingeborn B, Buonavoglia C, Berg M et al.Characterization of divergent and atypical canine coronaviruses from Sweden. Arch Virol 2007;152(8):1507-14.

9. Estola T. Coronaviruses, a New Group of Animal RNA Viruses. Avian Dis 1970;14 (2):330-6.

10. Fenollar F, Mediannikov O, Maurin M, Devaux C, Colson P, Levasseur A et al. SARS-CoV-2, and the Human-Animal Interface. Front Microbiol 2021;12:663815. doi.org/10.3389/fmicb.2021.

11. Garigliany M, Van Laere A, Clercx C, Giet D, Escriou N, Huon C. et al. SARS-CoV-2 natural transmission from human to cat. Emerg Infect Dis 2020;26(12):3069-71.

12. Hammer AS, Quaade ML, Mundbjerg K,
Boklund A, Halasa T, Belsham GJ, et al. SARSCoV-2 Transmission between Mink (Neovison vison) and Humans, Denmark. Emerg Infect Dis 2021;27(2):547-51.

13. Hewitt, JA, Lutz C, Florence WC, Pitt MLM, Rao $\mathrm{S}$, Rappaport J et al. ACTIVating resources for the COVID-19 pandemic: in vivo models for vaccines and therapeutics. Cell Host Microbe 2020;28(5):646-59.

14. Ho J, Hussein S, Sparagano O. Did the COVID-19 Pandemic Spark a Public Interest in Pet Adoption? Front Vet Sci 2021;8: 647308. doi. org/10.3389/fvets.2021.647308.

15. Hosie MJ, Hofmann-Lehmann R, Hartmann K, Egberink H, Truyen U, Addie DD. et al. Anthropogenic Infection of Cats during the 2020 COVID-19 Pandemic. Viruses 2021;13:185-98.

16. Kim, YI, Kim SG, Kim SM, Kim EA, Park SJ, $\mathrm{Yu} \mathrm{KM}$, et al. Infection and rapid transmission of SARS-CoV-2 in ferrets. Cell Host Microbe 2020;27:704-9.

17. Kiros M, Andualem H, Kiros T, Hailemichael W, Getu S, Geteneh A, et al. COVID-19 pandemic: current knowledge about the role of pets and other animals in disease transmission. Virol J 2020;17:143-8.

18. Kuo L. China confirms human-to-human transmission of coronavirus. The Guardian. Retrieved 2020 April. Available from: URL: https://www.theguardian.com/world/2020/ jan/20/coronavirus-spreads-to-beijing-aschina-confirms-new-cases.

19. Leroy EM, Gouilh MA, Brugere-Picoux J. The risk of SARS-CoV-2 transmission to pets and other wild and domestic animals strongly mandates a one-health strategy to control the COVID-19 pandemic. One Health 2020; 100133. doi.org/10.1016/j.onehlt.2020.100133.

20. Li JY, You Z, Wang Q, Zhou ZJ, Qiu Y, Luo R, Ge XY. The epidemic of 2019-novel-coronavirus (2019-nCoV) pneumonia and insights for emerging infectious diseases in the future. Microbes Infect 2020;22(2):80-5.

21. Li Q, Guan X, Wu P, Wang X, Zhou L, Tong $Y$, et al. Early Transmission Dynamics in Wuhan, China, of Novel Coronavirus-Infected Pneumonia. N Engl J Med 2020;382:1199-207.

22. Licitra BN, Duhamel GE, Whittaker GR. Canine 
enteric coronaviruses: emerging viral pathogens with distinct recombinant spike proteins. Viruses 2014;6(8):3363-76.

23. Lorusso A, Calistri P, Petrini A, Savini G, Decaro N. Novel coronavirus (SARS-CoV-2) epidemic: a veterinary perspective. Vet Ital 2020;56(1):510.

24. Mahdy MAA. The Impact of COVID-19 Pandemic on the Academic Performance of Veterinary Medical Students. Front Vet Sci 2020;7:594261. doi.org/10.3389/ fvets.2020.594261.

25. Middlemiss C, Voas S, Glossop C, Huey R. SARSCoV-2 in ferrets. Vet Rec 2021;188(2):133.

26. Molenaar RJ, Vreman S, Honing RW, Zwart R, de Rond J, Weesendorp E. et al. Clinical and Pathological Findings in SARS-CoV-2 Disease Outbreaks in Farmed Mink (Neovison vison). Vet Pathol 2020;57(5):653-57.

27. Newman A, Smith D, Ghai RR, Wallace RM, Torchetti MK, Loiacono C, et al. First reported cases of SARS-CoV-2 infection in companion animals-New York. MMWR Morb Mortal Wkly Rep 2020;69:710-3.

28. OIE. Infection with SARS-Cov2 in Animals 2021. Available from: URL: https://www.oie.int/ app/uploads/2021/05/en-factsheet-sars-cov-2. pdf.

29. OIE. Covid-19 Portal: Events in Animals. Available online: https://www.oie.int/ scientific-expertise/specific-informationandrecommendations/questions-and-answerson-2019novel-coronavirus/events-in-animals/ (accessed on 29 December 2020).

30. OIE. SARS-Cov-2 in Animals - Situation Report 1. Update during last month (01/05/202131/05/2021). Available from: URL:https:// www.oie.int/app/uploads/2021/06/sarscov-2situation-report-1.pdf.

31. Oreshkova N, Molenaar RJ, Vreman S, Harders F, Munnink BBO, Hakze van-der Honing RW. et al. SARS-CoV-2 infection in farmed minks, the Netherlands, Euro Surveill 2020;25(23):2001005. doi: 10.2807/1560-7917.ES.2020.25.23.2001005.

32. Oude Munnink BB, Sikkema RS, Nieuwenhuijse DF, Molenaar RJ, Munger E, Molenkamp R. et al. Transmission of SARS-CoV-2 on mink farms between humans and mink and back to humans. Science 2021;371:172-7.

33. Patterson EI, Elia G, Grassi A, Giordano A, Desario C, Medardo M. et al. Evidence of exposure to SARS-CoV-2 in cats and dogs from households in Italy, Nat Commun 2020;11(1):6231.

34. Pomorska-Mól M, Włodarek J, Gogulski M, Rybska M. Review: SARS-CoV-2 infection in farmed minks - an overview of current knowledge on occurrence, disease and epidemiology. Animal 2021;15(7):100272. doi: 10.1016/j.animal.2021.100272.

35. Poon LLM, D. Chu KW, Chan KH, Wong OK, Ellis TM, Leung YHC. et al. Identification of a Novel Coronavirus in Bats. J Virol 2005;79(4):2001-9.

36. Poudel U, Subedi D, Pantha S, Dhakal S. Animal coronaviruses and coronavirus disease 2019: Lesson for One Health approach. Open Vet J 2020;10(3):239-51.

37. Rottier PJM, Nakamura K, Schellen P, Volders H, Haijema BJ. Acquisition of macrophage tropism during the pathogenesis of feline infectious peritonitis is determined by mutations in the feline coronavirus spike protein. J Virol 2005;79:14122-30.

38. Salata C, Calistri A, Parolin C and Palù G. Coronaviruses: a paradigm of new emerging zoonotic diseases. Pathog Dis 2020;77(9):ftaa006. doi:10.1093/femspd/ftaa006.

39. Sharun K, Tiwari R, Patel SK, Karthik K, YatooMI, Malik YS, et al. Coronavirus disease 2019 (COVID-19) in domestic animals and wildlife: advances and prospects in the development of animal models for vaccine and therapeutic research, Hum Vaccin Immunother 2020;16(12):3043-54.

40. Shi J, Ye G, Shi K, Wan Y, Luo C, Aihara H. et al. Susceptibility of ferrets, cats, dogs, and other domesticated animals to SARS-coronavirus 2. Science 2020; 368(6494):1016-20.

41. Sit THC, Brackman CJ, Ip SM, Tam KWS, Law PYT, To EMW, et al. Infection of dogs with SARS-CoV-2. Nature 2020;586:776-8. 
42. Tekes G, Thiel HJ. Feline coronaviruses: pathogenesis of feline infectious peritonitis. In Advances in virus research. Cambridge MA 2016. Available from: URL: http://www. openveterinaryjournal.com.

43. Türk Veteriner Hekimleri Birliği (TVHB) Ana Sayfa-Basın Arşivi. 2020 tvhb.org.tr/basin-arsivi.

44. Wong ACP, Li X, Lau SKP, Woo PCY. Global Epidemiology of Bat Coronaviruses. Viruses 2019;11:174. doi: 10.3390/v11020174.

45. Woo PC, Lau SK, Lam CS, Lau CC, Tsang AK, Lau JH et al. Discovery of seven novel Mammalian and avian coronaviruses in the genus deltacoronavirus supports bat coronaviruses as the gene source of alphacoronavirus and betacoronavirus and avian coronaviruses as the gene source of gammacoronavirus and deltacoronavirus. J Virol 2012;86(7):3995-4008.

46. Yorguner N, Bulut NS., Akvardar Y. COVID-19 Salgını Sırasında Üniversite Öğrencilerinin Karşılaştığı Psikososyal Zorlukların ve Hastalığa Yönelik Bilgi, Tutum ve Davranışlarının İncelenmesi. Nöro Psikiyatri Arşivi 2020;58:310.

47. Zhou P, Yang XL, Wang XG, Hu B, Zhang L, Zhang W, et al. A pneumonia outbreak associated with a new coronavirus of probable bat origin. Nature 2020; 579:270-3. 